\title{
KARBON AKTIF DARI AMPAS BUAH MANGROVE SISA PEMBUATAN ZAT WARNA ALAMI MENGGUNAKAN AKTIVATOR $\mathrm{H}_{3} \mathrm{PO}_{4}$
}

\author{
Paryanto*, Wusana A. Wibowo, Ajeng L. Puspitaningrum, Ratri H. Hapsari \\ Program Studi Sarjana Teknik Kimia, Fakultas Teknik. Universitas Sebelas Maret \\ Jl. Ir. Sutami No. 36A, Surakarta 57126, Indonesia \\ *E-mail: paryanto.uns@gmail.com
}

\begin{abstract}
Abstrak
Ampas buah mangrove (spesies Rhizopora mucronata) merupakan limbah padat yang dihasilkan pada proses pembuatan zat warna alami. Pengurangan jumlah sekaligus peningkatan nilai ekonomi timbulan limbah padat ini dilakukan melalui pembuatan karbon aktif dengan proses pirolisis secara bacth. Penelitian ini bertujuan untuk mengetahui pengaruh variasi konsentrasi aktivator $\mathrm{H}_{3} \mathrm{PO}_{4}$ terhadap ukuran pori dan luas permukaan aktif karbon, serta daya jerap iodine. Metode penelitian meliputi proses penyiapan bahan baku yaitu mengambil ampas buah mangrove kering yang berukuran panjang $2 \mathrm{~cm}$ dengan diameter $0,75 \mathrm{~cm}$ sebanyak $0,5 \mathrm{~kg}$ kemudian dimasukkan ke dalam reaktor pirolisis dengan suhu rata-rata $351,83{ }^{\circ} \mathrm{C}$ hingga semиa ampas buah mangrove berubah menjadi karbon. Karbon tersebut kemudian direndam dalam larutan pengaktif $\mathrm{H}_{3} \mathrm{PO}_{4} 250 \mathrm{~mL}$ dengan variasi konsentrasi $(10 \%, 29 \%, 48 \%, 85 \%, 85 \%)$ selama $21 \mathrm{jam}$. Kemudian dilakukan pengujian karbon aktif dengan analisa ultimate proximate, analisa morfologi karbon aktif menggunakan Scanning Electron Microscope (SEM), dan analisa luas permukaan karbon aktif serta daya jerap iodine. Untuk hasil tertinggi dicapai pada perendaman dengan $\mathrm{H}_{3} \mathrm{PO}_{4} 85 \%$ daya jerap iodine sebesar 1.496,251 $\mathrm{mg} / \mathrm{gram}$, luas permukaan karbon aktif $1.874,835 \mathrm{~m}^{2} /$ gram dan jari-jari pori karbon aktif paling optimum adalah 8,629 $\mu \mathrm{m}$, ukuran pori yang dihasilkan termasuk dalam struktur mesopori.
\end{abstract}

Kata Kunci : ampas buah mangrove, pirolisis, karbon aktif, aktivator $\mathrm{H}_{3} \mathrm{PO}_{4}$

\section{PENDAHULUAN}

Berdasarkan data dari Badan Pusat Statistik, tahun 2012 kebutuhan karbon aktif di dalam negeri 35.942 ton per tahun. Pemanfaatan sumber daya alam lokal yang keberadaanya melimpah dapat membantu meningkatkan produksi karbon aktif dalam negeri serta dapat mengurangi impor karbon aktif yang masih tergolong cukup tinggi. Proses pengambilan zat warna alami dari buah mangrove spesies Rhizopora mucronata secara ekstrasi menyisakan timbulan limbah padat berupa ampas buah mangrove. Timbulan ampas padat tersebut belum pernah dimanfaatkan dengan maksimal. Ampas buah mangrove merupakan biomassa berkarbon yang memiliki potensi untuk dimanfaatkan sebagai karbon aktif.

Aktivasi pada karbon aktif yang berguna agar pori-pori karbon akan lebih terbuka sehingga luas permukaan karbon akan semakin besar yang menyebabkan lebih banyak molekul terserap. Aktivasi secara kimia dapat dilakukan dengan aktivator seperti $\mathrm{KOH}, \mathrm{NaOH}, \mathrm{ZnCl}_{2}$, $\mathrm{KCl}, \mathrm{H}_{3} \mathrm{PO}_{4}$, dan $\mathrm{HCl}$, hal ini menyebabkan pengotor terbawa oleh zat pengaktif.
Penggunaan aktivator tersebut memberikan efek yang berbeda-beda terhadap luas permukaan maupun volume pori karbon aktif yang dihasilkan. Hal tersebut disebabkan karena kondisi, prosedur dan pengaruh konsentrasi dan rasio impregnasi aktivator (Jibril dkk.,2007). Hasil pengamatan menunjukkan variasi konsentrasi aktivator dapat meningkatkan luas permukaan dan berpengaruh terhadap daya adsorpsi karbon aktif dihasilkan.

Karbon aktif terbarukan dari tandan kosong sawit dimanfaatkan untuk adsorpsi asam merah. Produksi karbon aktif melalui aktivasi secara kimia dengan menggunakan kalium hidroksida $(\mathrm{KOH})$. Central composite design (CDD) digunakan dalam penentuan kondisi dalam kemampuan adsorpsi karbon aktif pada asam merah. Kapasitas adsorpsi 197.62 mg/g (98.81\%) dan diperoleh yield sebesar $19.12 \%$ pada suhu pirolisis $820^{\circ} \mathrm{C}$ dan 140 menit. Karbon aktif yang optimum memiliki luas permukaan $820 \mathrm{~m}^{2} / \mathrm{g}$, volume pori-pori 0.52 $\mathrm{cm} 3 / \mathrm{g}$ dan pengujian SEM dilakukan untuk menentukan morfologi permukaan sehingga 
dapat meningkatkan kemampuan adsorpsi karbon aktif pada asam merah (Auta, Manase, 2012). Selain itu, masih terdapat lagi penelitian tentang karbon aktif yang berasal dari buah kelapa kosong tandan (EFB) ini yang bermafaat untuk menemukan kesesuaian aplikasi untuk penghapusan fenol dalam larutan melalui proses adsorpsi. Aplikasi karbon aktif yang berasal dari tandan kosong sawit dalam proses adsorpsi fenol. Variasi suhu pada proses pirolisis yaitu 300,500 dan $800{ }^{\circ} \mathrm{C}$ serta waktu pirolisis 6 jam. Hasil yang didapat bahwa karbon aktif dengan suhu pirolisis $800^{\circ} \mathrm{C}$ memiliki kapasitas penyerapan terbesar pada larutan fenol terindikasi dengan nilai keasaman $(\mathrm{pH}<2$ 3) dengan konsentrasi awal fenol (200-300 mg/L) (Alam, Md. Zahangir,2007).

Pengaruh kadar abu pada tandan kosong sawit sebagai umpan dalam pembuatan karbon aktif dilakukan menggunakan analisa proksimat, analisa SEM dan analisa bahan baku. Kadar abu pada umpan berkisar 1,60 sampai $5.29 \mathrm{mf}$ wt \% kemudian melalui proses pirolisis pada suhu $550^{\circ} \mathrm{C}$ dalam waktu 1 jam. Bahan baku dengan kadar abu (1.60 mf wt \%) menghasilkan persentase karbon terendah (23.05 wt \%) dengan persentase karbon tertinggi (88.34 mf wt \%). Penuruan kadar abu pada umpan menghasilkan perubahan signifikan dalam struktur morfologi karbon yang dihasilkan. Luas permukaan karbon aktif maksimum (11.1200 m2 g-1) diperoleh pada umpan yang memilki kadar abu sebesar $2.21 \mathrm{mf}$ wt \% (Shariff, Adilah, 2014). Karakteristik bahan bakar, profil pembakaran dan studi kinetik arang yang telah di pirolisis di 300, $500^{\circ} \mathrm{C}$ diselidiki $\mathrm{RH}$ (sekam padi), WC (kayu chips) dan WP (kayu pelet). Ketika suhu pirolisis yang lebih tinggi digunakan, nilai kalorinya menjadi sebanding dengan rasio bahan bakar dan berbanding terbalik dengan zatnya (Park, Sang-Woo, 2012).

Pirolisis sour cerry dengan aktivator $\mathrm{ZnCl}_{2}$ menggunakan pencampuran $20 \mathrm{~g}$ sour cerry dalam larutan $\mathrm{ZnCl}_{2}$ selama 24 jam, suhu $80{ }^{\circ} \mathrm{C}$ serta ratio impregnasi $1: 1,2: 1,3: 1,4: 1$ pada suhu pirolisis $700^{\circ} \mathrm{C}$ dan waktu pirolisis adalah 1 jam menghasilkan volume pori $1.566 \mathrm{~cm}^{3} / \mathrm{g}$ dan luas permukaan karbon aktif $1704 \mathrm{~m}^{2} / \mathrm{g}$ (Angin, Dilek, 2014). Adapula pembuatan karbon aktif dari kakao menggunakan aktivator $\mathrm{H}_{2} \mathrm{SO}_{4}$ dengan metode perendaman selama 24 jam, pencucian dengan distilled water kemudian dikeringkan dengan oven $\left(60{ }^{\circ} \mathrm{C}\right)$ melalui variasi suhu pirolisis $(215,330,415$, $510,750,900)^{\circ} \mathrm{C}$, luas permukaan karbon aktif yang dihasilkan $2000 \mathrm{~m}^{2} / \mathrm{g}$ (Recobert, M. Plaza, 2017). Selain itu, masih terdapat lagi penelitian tentang karbon aktif yang berasal dari oily sludge dengan aktivator $\mathrm{KOH}$ melalui perendaman selama 24 jam, pencucian dengan distilled water yang kemudian dikeringkan dengan oven $\left(60^{\circ} \mathrm{C}\right)$ dan kondisi operasi saat pirolisis adalah $420{ }^{\circ} \mathrm{C}$ dalam waktu 110 menit menghasilkan luas permukaan karbon aktif $3292 \mathrm{~m}^{2} / \mathrm{g}$ dengan kapasitas penyerapan 64.6 mL/0.1 (Wang, Jun, 2017).

Pemanfaatan rumput laut "gulf-weed" menjadi karbon aktif dengan suhu pirolisis $600^{\circ} \mathrm{C}$ dalam waktu 120 menit menggunakan aktivator $\mathrm{KOH}$ rasio impregnasi 4:1 dengan aktivasi pada suhu $850^{\circ} \mathrm{C}$ dalam waktu 120 menit, luas permukaan karbon aktif yang dihasilkan $3362 \mathrm{~m}^{2} / \mathrm{g}$ serta jari-jari atau volume pori sebesar $3,08 \mathrm{~cm}^{3} / \mathrm{g}$ (Shijie, 2017). Kemudian adapula penelitian tentang karbon aktif terbarukan dari limbah karpet, produksi karbon aktif melalui aktivasi secara kimia dengan menggunakan $\mathrm{H}_{3} \mathrm{PO}_{4}$. Kapasitas adsorpsi $769.2 \mathrm{mg} / \mathrm{g}$ pada suhu pirolisis $700^{\circ} \mathrm{C}$ selama 4 jam. Karbon aktif yang optimum memiliki luas permukaan $953 \mathrm{~m}^{2} / \mathrm{g}$, jari-jari pori-pori $1.48 \mathrm{~nm}$ (Hassan, Asaad F., 2017). Karbon aktif yang berasal dari kacang pistachio dengan aktivator nitrogen dengan suhu $850{ }^{\circ} \mathrm{C}$ dalam waktu 20 menit dan kondisi operasi saat pirolisis adalah $600{ }^{\circ} \mathrm{C}$ dalam waktu 60 menit menghasilkan luas permukaan karbon aktif $2596 \mathrm{~m}^{2} / \mathrm{g}$ (Niksiar, Arezou, 2017). Karbon aktif dari cangkang kelapa sawit dipirolisis dalam waktu 4 jam dengan suhu pirolisis 500 ${ }^{\circ} \mathrm{C}$ menggunakan aktivator $\mathrm{KOH}$ dengan rasio impregnasi $1: 4$ pada suhu $100{ }^{\circ} \mathrm{C}$ dalam waktu 4 jam. Hasil dari penelitian ini yaitu karbon aktif dengan jari-jari pori 1,4-9,3 $\mathrm{nm}$ dan luas permukaan karbon aktif $462,1 \mathrm{~m}^{2} / \mathrm{g}$ (Misnon, Izan zwan, 2015).

\section{METODOLOGI \\ 2.1 Bahan}

Bahan yang digunakan dalam penelitian ini adalah ampas buah mangrove spesies Rizhopora Mucronata sisa hasil ekstraksi zat warna alami berbasis air. Buah mangrove diperoleh dari wilayah Cilacap, Jawa Tengah. Larutan Asam fosfat $\left(\mathrm{H}_{3} \mathrm{PO}_{4}\right)$ dengan kadar $85 \%$ PT.Brataco, Bandung. 


\subsection{Alat}

Rangkaian alat pirolisis batch (Gambar 1) terdiri dari tabung gas LPG $3 \mathrm{~kg}$ (1), regulator (2), kran gas tipe ball-valve (3), termocouple keramik $\sim 1.000^{\circ} \mathrm{C}$ (4), reaktor pirolisis (5), termometer payung $\sim 500^{\circ} \mathrm{C}$ (6), kondensor (7), kipas radiator (8), pompa sirkulasi (9), radiator penukar panas (10), pipa keluaran kondensat (11).

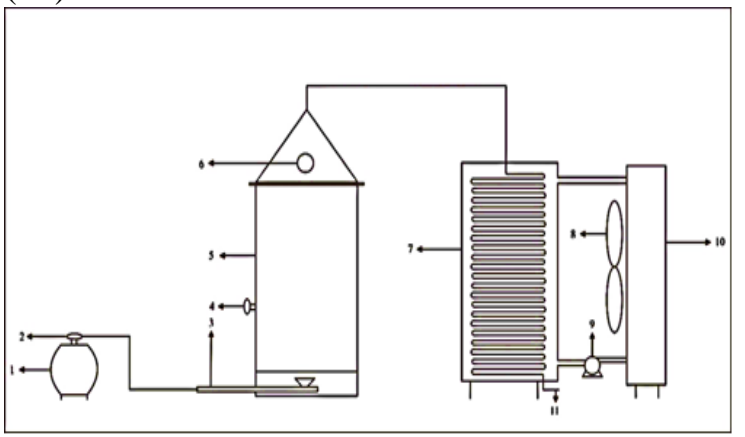

Gambar 1. Rangkaian Alat Pirolisis Batch

\subsection{Cara Kerja}

Ampas buah mangrove yang telah dijemur hingga kering sebanyak $0,5 \mathrm{~kg}$ dimasukkan ke dalam reaktor pirolisis, kemudian dipanaskan sampai suhu konstan dengan rata-rata suhu yaitu $351,83{ }^{\circ} \mathrm{C}$ hingga semua ampas buah mangrove berubah menjadi arang. Berat arang yang dihasilkan 180 gr.

Karbon yang telah terbentuk kemudian dihaluskan lalu disaring dengan ayakan ukuran 200 mesh. Karbon tersebut kemudian direndam dalam larutan pengaktif $\mathrm{H}_{3} \mathrm{PO}_{4} 250 \mathrm{~mL}$ dengan variasi konsentrasi $(10 \%, 29 \%, 48 \%, 85 \%$, $85 \%$ ) selama 21 jam. Setelah perendaman, karbon aktif disaring dan dicuci dengan aquadest hingga $\mathrm{pH}$ netral. Karbon yang telah diaktivasi secara kimia lalu dioven pada suhu $100{ }^{\circ} \mathrm{C}$ selama 3 jam untuk mengurangi kadar airnya. Setelah proses penyiapan bahan karbon aktif selesai, karbon aktif dari ampas buah mangrove dibiarkan dingin dan disimpan dalam desikator.

\subsection{Analisis}

Metode analisa yang digunakan yaitu dengan analisa ultimate proximate untuk mengetahui kadar abu dan moisture pada karbon aktif, analisa morfologi karbon aktif menggunakan scanning electron microscope (SEM) merk Jeol tipe 650 , analisa luas permukaan karbon aktif dan daya jerap iodine menggunakan alat analisa BET merk Nova tipe 4200 e, dan analisa luas dan jari-jari pada pori karbon aktif menggunakan alat merk Jeol tipe 650 .

\section{HASIL DAN PEMBAHASAN \\ 3.1 Analisa Ultimate Proximate.}

Kandungan dari karbon aktif dianalisis dengan menggunakan analisa ultimate proximate, dan nilai kalor di Laboratorium Tekmira Bandung. Analisis ultimate proximate meliputi moisture in air-dried sample $(6,48 \%)$, abu $(3,05 \%)$, volatile matter $(41,91 \%)$, fixed carbon (48,56\%) masih memenuhi standar mutu karbon aktif SNI 06-3730-1995 yaitu moisture in air-dried sample $(\leq 15 \%)$, abu $(\leq$ $10 \%)$, volatile matter $(\leq 15 \%)$, fixed carbon (min $65 \%$ ). Analisa ulitmate meliputi karbon $(62,90 \%)$, hidrogen $(4,79 \%)$, nitrogen $(2,87 \%)$, sulphur $(0,03 \%)$, oxygen $(26,36 \%)$ dengan nilai total kalor $5.523 \mathrm{cal} / \mathrm{g}$ yang masih masuk dalam range Standar mutu karbon aktif yaitu 4.400$7.300 \mathrm{kkal} / \mathrm{kg}$ (Paryanto, 2014).

\subsection{Analisa Morfologi Karbon Aktif menggunakan Scanning Electron Microscope (SEM).}

Morfologi karbon aktif dari ampas buah mangrove dapat diamati dengan menggunakan Scanning Electron Microscope (SEM) dengan merk Jeol tipe 650. SEM dapat memberikan gambaran secara terperinci mengenai morfologi permukaan, yaitu spesifik pada partikel karbon dan pori pada permukaan karbon aktif. Berikut ini adalah gambar dari hasil uji SEM:

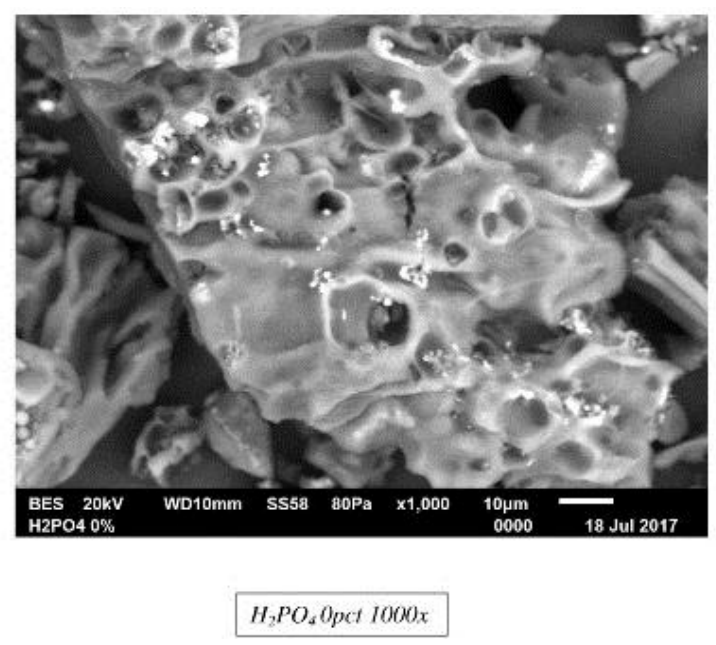

(a) 


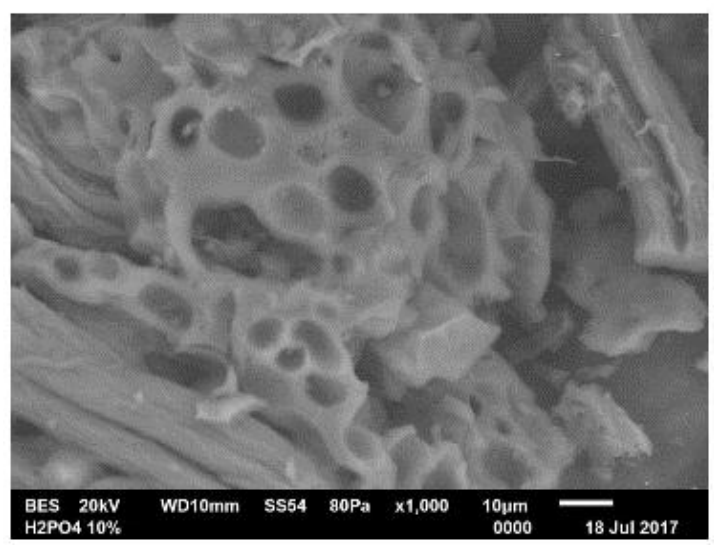

$\mathrm{H}_{2} \mathrm{PO}_{4}$ JOpct $\mathrm{lOOON}$

(b)

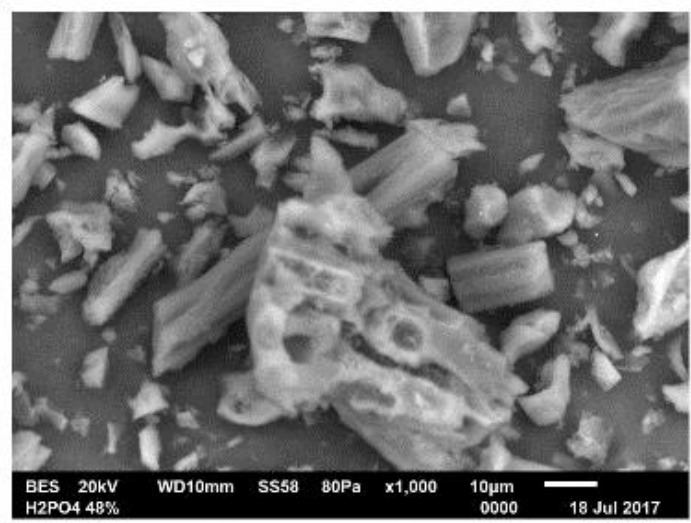

$\mathrm{H}_{2} \mathrm{PO}_{4} 48$ pet $\mathrm{J} 000 \mathrm{x}$

(c)

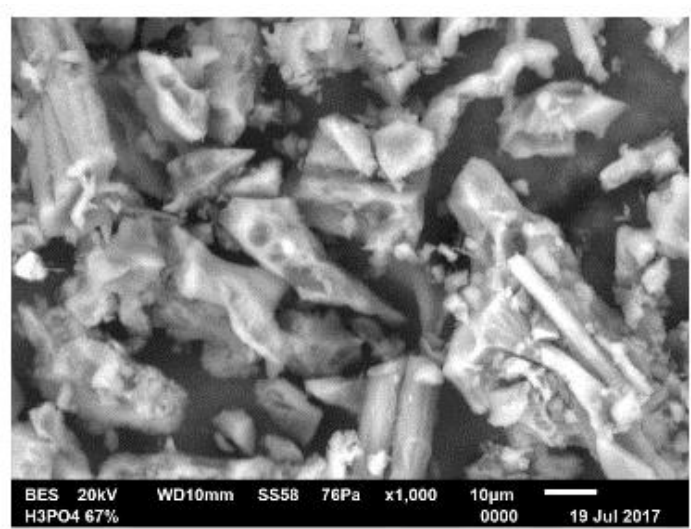

$\mathrm{H}_{2} \mathrm{PO}_{4} 67$ pct $1000 x$

(d)

Gambar 2. Hasil SEM Karbon Aktif Tanpa $\mathrm{H}_{3} \mathrm{PO}_{4}(\mathrm{a}), \mathrm{H}_{3} \mathrm{PO}_{4} 10 \%$ (b), $\mathrm{H}_{3} \mathrm{PO}_{4}$ $48 \%$ (c), KOH $67 \%$ (d)

\subsection{Analisa Luas Permukaan Karbon Aktif dan Daya Jerap Iodine.}

Daya jerap atau adsorpsi arang aktif pada iodine memperlihatkan kemampuan arang aktif utnuk mengadsorpsi kompnen dengan bobot molekul rendah (Suzuki,2007). Aktivator $\mathrm{H}_{3} \mathrm{PO}_{4}$ berperan membentuk pori pada arang. Semakin banyak pori yang terbentuk maka iodine yang terjerap akan semakin banyak pula.

Pada tabel 1 dapat disimpulkan bahwa karbon aktif dengan aktivator $\mathrm{H}_{3} \mathrm{PO}_{4}$ pada konsentrasi $85 \%$ memiliki luas permukaan $1874,835 \mathrm{~m}^{2} / \mathrm{g}$ dimana lebih besar jika dibandingkan dengan luas permukaan tanpa aktivator sebesar 1200,678 $\mathrm{m}^{2} / \mathrm{g}$ dan karbon aktif pada konsentrasi $\mathrm{H}_{3} \mathrm{PO}_{4} 85 \%$ dengan daya jerap 1496,251 mg/g lebih tinggi nilainya jika dibandingkan dengan daya jerap iodine pada karbon aktif tanpa aktivator yaitu 745,235 $\mathrm{mg} / \mathrm{g}$. Hal ini menunjukkan bahwa nilai luas permukaan dan daya jerap iodine semakin besar seiring dengan penambahan konsentrasi $\mathrm{H}_{3} \mathrm{PO}_{4}$ pada karbon. Penambahan konsentrasi $\mathrm{H}_{3} \mathrm{PO}_{4}$ dari $0-85 \%$ memiliki hubungan lurus dengan luas permukaan arang aktif.

Tabel 1. Analisa Luas Permukaan (BET) dan Daya Jerap Iodine

\begin{tabular}{cccc}
\hline No. & $\begin{array}{c}\text { Kosentrasi } \\
\text { (\% massa })\end{array}$ & $\begin{array}{c}\text { Luas } \\
\text { Permukaan } \\
\left(\mathrm{m}^{2} / \mathrm{g}\right)\end{array}$ & $\begin{array}{c}\text { Daya } \\
\text { Jerap } \\
\text { Iodine } \\
(\mathrm{mg} / \mathrm{g})\end{array}$ \\
\hline 1. & $\begin{array}{c}\mathrm{Tanpa}_{4} \\
\mathrm{H}_{3} \mathrm{PO}_{4}\end{array}$ & 1200,678 & 745,235 \\
2. & $10 \%$ & 1318,782 & 896,801 \\
& $\mathrm{H}_{3} \mathrm{PO}_{4}$ & & \\
3. & $29 \%$ & 1398,460 & 1121,602 \\
& $\mathrm{H}_{3} \mathrm{PO}_{4}$ & & \\
4. & $48 \%$ & 1487,032 & 1201,361 \\
& $\mathrm{H}_{3} \mathrm{PO}_{4}$ & & \\
5. & $67 \%$ & 1638,321 & 1320,521 \\
& $\mathrm{H}_{3} \mathrm{PO}_{4}$ & & \\
6. & $85 \%$ & 1874,835 & 1496,251 \\
& $\mathrm{H}_{3} \mathrm{PO}_{4}$ & &
\end{tabular}

3.4 Analisa Luas Pori dan Jari-Jari Pori pada Karbon Aktif.

Dari Gambar 2 terlihat adanya perubahan struktur pori karbon yang diaktivasi oleh $\mathrm{H}_{3} \mathrm{PO}_{4}$. Morfologi karbon aktif dengan aktivasi 
$\mathrm{H}_{3} \mathrm{PO}_{4} 10 \%$ memiliki jari-jari pori $8,629 \mu \mathrm{m}$, ukuran pori yang dihasilkan termasuk ke dalam struktur mesopori. Pori-pori tersebut merupakan ukuran pori-pori yang paling optimum.

Tabel 2. Analisa Luas Permukaan Pori dan Jari-jari Pori

\begin{tabular}{cccc}
\hline No. & $\begin{array}{c}\text { Konsentrasi } \\
\mathrm{H}_{3} \mathrm{PO}_{4} \\
(\% \text { massa })\end{array}$ & $\begin{array}{c}\text { Luas Pori } \\
\left(\mathrm{m}^{2} / \mathrm{g}\right)\end{array}$ & $\begin{array}{c}\text { Jari-Jari } \\
\text { Pori } \\
(\mu \mathrm{m})\end{array}$ \\
\hline 1. & $\begin{array}{c}\text { Tanpa } \\
\mathrm{H}_{3} \mathrm{PO}_{4}\end{array}$ & 891 & 16,845 \\
2. & $10 \% \mathrm{H}_{3} \mathrm{PO}_{4}$ & 233,8 & 8,629 \\
3. & $29 \% \mathrm{H}_{3} \mathrm{PO}_{4}$ & 785,8 & 14,635 \\
4. & $48 \% \mathrm{H}_{3} \mathrm{PO}_{4}$ & 1337,8 & 20,641 \\
5. & $67 \% \mathrm{H}_{3} \mathrm{PO}_{4}$ & 867,2 & 16,619 \\
6. & $85 \% \mathrm{H}_{3} \mathrm{PO}_{4}$ & 2412,7 & 32,336 \\
\hline
\end{tabular}

\section{KESIMPULAN}

Luas permukaan dan daya jerap iodine yang paling tinggi terdapat pada sampel arang aktif dengan konsentrasi $\mathrm{H}_{3} \mathrm{PO}_{4} 10 \%$ dengan nilai berturut turut $1874,835 \mathrm{~m}^{2} / \mathrm{g}$ dan 1496,251 $\mathrm{mg} / \mathrm{g}$. Jari-jari pori karbon aktif yang paling optimum $8,629 \mu \mathrm{m}$ yaitu karbon aktif dengan aktivasi $\mathrm{H}_{3} \mathrm{PO}_{4} 10 \%$.

\section{UCAPAN TERIMAKASIH}

Tim peneliti mengucapkan terima kasih kepada Dirjen Risetdikti dan LPPM UNS atas pemberian pendanaannya melalui skema riset PTUPT serta koordinator laboratorium Dasar Teknik Kimia dan laboratorium Power House Teknik Kimia yang telah memberi kesempatan melakukan penelitian.

\section{DAFTAR PUSTAKA}

Alam, Md. Zahangir., (2007), Activated Carbons Derived From Oil Palm EmptyFruit Bunches: Application to Environmental Problems, Journal of Environmental Sciences 19 (2007) 103108.

Angin, Dilek., (2014), Production and characterization of activated carbon from sour cherry stones by zinc chloride, Journal of Fuel 115 (2014) 804-811.

Auta, Manase., (2012), Preparation of Activated Carbon From Oil Palm Fruit Bunch for the Adsorption of Acid Red 1 Using Optimized Response Surface Methodology, Journal of Engineering Research and Applications (IJERA) ISSN: 2248-9622 Vol. 2, Issue 3, pp.1805-1815.

Claoston, N., (2014), Effects of Pyrolysis Temperature on the Physicochemical Properties of Empty Fruit Bunch and Rice Husk Biochars, Waste Management \& Research 2014, Vol. 32(4) 331-339.

Hassan, Asaad F., (2017), Production of activated carbons from waste carpets and its application in methylene blue adsorption:Kinetic and thermodynamic studies, Journal of Environmental Chemical Engineering 5 (2017) 955-963

Jibril, B., O. Houache, A. Al-Maamari, B. AlRashidi., (2008). Effects of $\mathrm{H}_{3} \mathrm{PO}_{4}$ and $\mathrm{KOH}$ in Carbonization of Lignocellulosic Material, J Anaytical Applied Pyrolysis, (83):151-156.

Jun Wang., (2017), Production and characterization of high quality activated carbon from oily, Journal of Fuel Processing Technology 162, pp.13-19.

Li, Shijie., (2017), Preparation and characterization of super activated carbon produced from gulfweed by $\mathrm{KOH}$ activation, Journal of Microporous and Mesoporous Materials 243, pp.291-300.

Misnon, Izan Izwan., (2015), Electrochemical properties of carbon from oil palm kernel shell for high performance supercapasitors, Journal of Electrochimica acta 174, pp.78-86

Niksiar, Arezou., (2017), Activated carbon preparation from pistachio shell pyrolysis and gasification in a spouted bed reactor, Journal of Biomass and Bioenergy 106, pp.43-50.

Park, Sang-Woo., (2012), Effects of Pyrolysis Temperature on Changes in Fuel Characteristics of Biomass Char. Department of Environmental Engineering, Hanbat National.

Paryanto., (2014), Activated Carbon from Mangroves Waste Rest of Extraction from Making Natural Color, Forum Tahunan Pengembangan Iptek dan Inovasi Nasional IV. 
Recobert, M. Plaza., (2017), Preparation of binderless activated carbon monoliths from cocoa bean Husk, Journal of Microporous and Mesoporous Materials, $243: 28-38$.

Shariff, Adilah., (2014), Slow Pyrolysis of Oil Palm Empty Fruit Bunches for Biochar Production and Characterisation, Journal of Physical Science, Vol. 25(2), 97-112. 